\title{
SOX17 and RASSAF1A Promoters Methylation in Circulation Tumor Cell and Cell Free Deoxyribonucleic Acid Isolated from Plasma in Breast Cancer
}

\author{
${ }^{1}$ Ferdous A Jabir, ${ }^{2}$ Sundus K Hamzah
}

\begin{abstract}
Purpose: The study was to evaluate SOX17, and RASSEF $1 \mathrm{~A}$ promoters methylation levels in patients with malignant breast tumors compared with healthy women.

Materials and methods: Fifty women with breast cancer (range 26 to 75 years) were included in this study. They were admitted at Al-Diwaniyah Teaching Hospital, Iraq, compared with 25 women as the control. We obtained plasma samples from 50 patients (breast cancer) stages II, III, IV and normal (healthy women). Cell-free deoxyribonucleic acid (DNA) (cfDNA) extracted and methylation analysis for SOX17 and RASSEF1A gene.
\end{abstract}

Results: We found different methylation pattern of the RASSEF1A gene in plasma samples between patients with breast cancer and control $(p<0.05)$ ranging in all cases $30(60 \%)$ and unmethylation in $20(40 \%)$, hyper methylation frequency in all studied cases [13 (44.8\%) for II stage, $12(80 \%)$ III stage and 4 (66.6\%) IV stage of breast cancer in this study association between the hypermethylation was significant with age $\geq 5011.4(71.2 \%)$ and $<5026(76 \%)]$ than normal cases, we found different methylation pattern of the SOX17 gene in plasma samples between patients with breast cancer and control $(p<0.05)$ ranging in all cases $29(58 \%)$ and unmethylation in $21(42 \%)$,hyper methylation frequency in all studied cases 11 (37.9\%) for II stage, $13(86.6 \%)$ III stage and $5(83.3 \%)$ IV stage of breast cancer in this study association between the hyper methylation was significant with age $(\geq 50$ $13(81.2 \%)$ and $<5023(67 \%)$ than normal cases also this study association between the hypermethylation was significant with menopause (premenopause $6(66 \%)$, post menopause 31 $(75.6 \%)$ than the control group $(0 \%)$.

Conclusions: Our data indicate that methylation of the RASSAF1A and SOX17 genes are the frequent event in primary breast cancer and that it plays a major role in the silencing of the expression of this gene during tumor development.

Keywords: Breast cancer, Cell-free deoxyribonucleic acid (DNA) Methylation, RASSAF1A gene, SOX17 gene.

\footnotetext{
1,2Lecturer

${ }^{1}$ Department of Biochemistry, College of Medicine, University of Al-Qadisiyah, Al-Qadisiyah, Iraq

${ }^{2}$ Department of Chemistry, College of Education, University of Al-Qadisiyah, Al-Qadisiyah, Iraq

Corresponding Author: Sundus K Hamzah, Chemistry Department, College of Education, University of Al-Qadisiyah, Al-Qadisiyah, Iraq, Mobile: 07818649742, e-mail:sundus. hamzah@qu.edu.iq
}

How to cite this article: Jabir FA, Hamzah SK. SOX17 and RASSAF1A Promoters Methylation in Circulation Tumor Cell and Cell Free Deoxyribonucleic Acid Isolated from Plasma in Breast Cancer. Indian J Med Biochem 2018;22(2):108-113.

Source of support: Nil

Conflict of interest: None

\section{INTRODUCTION}

Breast cancer is the most common malignancy among women worldwide. ${ }^{1,2}$ The prognosis of this disease mainly depends on its early detection, which currently to a major part relies on mammography. Early detection of this disease can also be facilitated by new diagnostic biomarkers ${ }^{3}$ cell-free DNA (cfDNA) and circulating tumor cells (CTCs), released into the bloodstream by solid tumors, are considered real-time liquid biopsies in cancer patients reflecting the disease complexity and progression. The liquid biopsy represents a surrogate material for the molecular characterization of solid cancers. ${ }^{4}$ In fact, in the advanced stages when the tumor has acquired genetic, epigenetic and expression features which may be very different from those of the primary tissue, the liquid biopsy represents the actual molecular signature of the disease. Total cfDNA concentration, higher in cancer patients than healthy individuals, ${ }^{5}$ has been proposed as a cancer marker, but it has shown limited sensitivity and specificity. ${ }^{6,7}$ DNA methylation acts as a major epigenetic mechanism within the complex network of mechanisms regulating gene expression. ${ }^{8}$ The chemically stable addition of a methyl $\left(\mathrm{CH}_{3}\right)$ group at the carbon five positions of the cytosine ring by DNA methyltransferases (DNMTs) interferes with the capacity of several proteins to bind DNA. ${ }^{9}$ Methylation in CpG-rich gene promoters serves as recognition signals for proteins mediating transcriptional repression and constitutes a mechanism for gene regulation. ${ }^{10,11}$ Methylation in repetitive transposable elements plays an important role in their silencing and contributes to global genomic stability ${ }^{12-14}$ Physiologically methylation patterns are established during early embryogenesis.

Ras association domain family one isoform (ARASSF1A) is a tumor suppressor gene, whose inactivation, mainly achieved by promoter hypermethylation, is involved in the development of many cancers. ${ }^{15}$ So far the role 
of RASSF1A methylation as a biomarker in cfDNA has been investigated, mostly in combination with other parameters, in a variety of tumor such as breast cancer. ${ }^{16}$ Methylation of RASSF1A increases significantly with advancing clinical stage, suggesting that the inactivation of this gene is associated with tumor progression ${ }^{17}$ RASSF1A promoter hypermethylation has been detected in cfDNA from melanoma patients ${ }^{18}$ in association to a worse response to therapy and reduced overall survival. ${ }^{19}$ In melanom ${ }^{20}$ SOX17, a member of the Sry-related highmobility group box gene family is a high-mobility group box transcription factor that is known to function as a key regulator in various developmental and disease contexts, including endoderm organ development, ${ }^{21,22}$ vascular development, ${ }^{23}$ and stem cell function regulation. ${ }^{24}$ Besides, SOX17 also plays an essential role in human carcinogenesis Hypermethylation of the SOX17 promoter is correlated with poor prognosis in several cancers ${ }^{25}$ In a previous study, we demonstrated that SOX17 is often hypermethylated and provides important prognostic information in breast cancer patients. Recent studies have shown that SOX17 is also epigenetically silenced in circulating tumor cells isolated from the peripheral blood of patients with breast or gastric cancer ${ }^{26}$ and that such silencing can be used as a molecular diagnostic marker in stage cancer. Therefore, this study aimed to evaluate the prognostic significance of SOX17 promoter methylation in breast cancer cancer (Fig. 1). ${ }^{27,28}$

\section{MATERIALS AND METHODS}

\section{Study Patients}

A total of 50 women with breast cancer (range 26 to 75 years) were included in this study. They were admitted at Al-Diwaniyah Teaching Hospital, Iraq, compared with 25 women as the control. We obtained plasma samples from 50 patients (breast cancer) stage II, III, IV and normal (healthy women). This study was conducted during the period from September 2016 to April 2017, were analyzed and compared to determine the tumor.

Cell-free DNA was extracted blood $(5 \mathrm{~mL})$ was collected in K3 EDTA-containing tubes. The plasma was isolated by low-speed centrifugation: $500 \times \mathrm{g}$ for 10 minutes using centrifuge (Gottingen, Germany). It was (cfDNA) was isolated from $2 \mathrm{~mL}$ plasma using was synthesized using M-MLV cfDNA synthesis kit (Quick-cfDNATM serum and plasma DNA miniprep kit, USA) Transcript expression was evaluated using gene-specific primers unmethylation $(R A S S F 1 A)^{\mathrm{TM}} 57^{\circ} \mathrm{C}$ with the following cycling parameters: followed by 40 cycles and methylation $(R A S S F 1 A)^{\mathrm{TM}} 58^{\circ} \mathrm{C}$ with the following cycling parameters: followed by 40 cycles the PCR products were examined by electropho- resis polymerase chain reaction (PCR) conditions were as follows: $95^{\circ} \mathrm{C}$ for $4 \mathrm{~min}$ and then 40 cycles of $95^{\circ} \mathrm{C}$ for 40 seconds, $58^{\circ} \mathrm{C}$ for 20 seconds, and $72^{\circ} \mathrm{C}$ for 30 seconds, with a final extension for 5 minutes at $72^{\circ} \mathrm{C}$.

Also, unmethylation (SOX17) $\mathrm{Tm}(58)^{\circ} \mathrm{C}$ with the following cycling parameters: followed by 40 cycles and methylation $(S O X 17)^{\mathrm{TM}}(59)^{\circ} \mathrm{C}$ with the following cycling parameters: followed by 40 cycles the PCR products were examined by electrophoresis PCR conditions were as follows: $95^{\circ} \mathrm{C}$ for 4 minutes and then 40 cycles of $95^{\circ} \mathrm{C}$ for 40 seconds, $59^{\circ} \mathrm{C}$ for 20 seconds, and $72^{\circ} \mathrm{C}$ for 30 seconds, with a final extension for 5 minutes at $72^{\circ} \mathrm{C}$.

\section{Methylation Analysis}

Genomic DNA was extracted and treated with bisulfite by using the EZ Methylation ${ }^{\mathrm{TM}}$ Kit (USA). Methylation specific PCR (MSP) primers of four selected candidate genes were prepared as described previously. ${ }^{26} \mathrm{MSP}$ was performed using $5 \mu \mathrm{L}$ of modified cfDNA (USA) PCR system Furthermore, the methylation was calculated from threshold cycles (CT) values. Lastly, MSPs were analytically validated using methylated DNA by using gene-specific primers methylation (RASSAF1A) (MR) (5'-CCC TCC CAA ACG CCG A-3') MF (5'-GCT AAC AAA CGA GAA CCG-3' $3^{\mathrm{TM}} 58^{\circ} \mathrm{C}$ and unmethylated $\left(57^{\circ} \mathrm{C}\right.$ with the following cycling parameters: followed by 40 cycles, also MSPs were analytically validated using methylated DNA by using gene-specific primers methylation $(S O X 17)^{\mathrm{TM}} 59^{\circ} \mathrm{C}$ and methylated $58^{\circ} \mathrm{C}$ MR (5'-TTG CGT TAG TCG TTT GCG TTC-3') MF (5'-CAA AAA CGA ATC CCG TAT CCG ACG-3') with the following cycling parameters: followed by 40 cycles.

\section{Statistical Analysis}

By using Statistical Package for the Social Sciences (SPSS version 23), student test (t-test) was used for the quantitative data. The lowest level of significance was when the probability $(\mathrm{p}<0.05)$.

\section{RESULTS}

We found different methylation pattern of the RASSEF1A gene in plasma samples between patients with breast cancer and control $(\mathrm{p}<0.05)$ ranging in all cases $30(60 \%)$ and unmethylation in $20(40 \%)$, hypermethylation frequency in all studied cases [13(44.8\%) for IIstage, $12(80 \%)$ III stage and $4(66.6 \%)$ IV stage] of breast cancer in this study association between the hypermethylation was significant with age [ $\geq 5011.4(71.2 \%)$ and $5026(76 \%)]$ than normal cases also this study association between the hypermethylation was significant with Menopause [premenopause $5(55 \%)$, postmenopause $27.3(65.8 \%)$ ] 
than control group $(0 \%)$ as shown in Figures $2 \mathrm{~A}$ and B and Table 1.

We found different methylation pattern of the SOX17 gene in plasma samples between patients with breast cancer and control $(\mathrm{p} \leq 0.05)$ ranging in all cases $29(58 \%)$ and unmethylation in $21(42 \%)$, hypermethylation frequency in all studied cases [11 (37.9\%) for II stage, $13(86.6 \%)$
III stage and $5(83.3 \%)$ IV stage] of breast cancer in this study association between the hypermethylation was significantly with age $\left[\geq 50^{13}(81.2 \%)\right.$ and $\left.5023(67 \%)\right]$ than normal cases also this study association between the hypermethylation was significant with Menopause (premenopause 6 (66\%), postmenopause $31(75.6 \%)$ than control group $(0 \%)$ as shown in Figures $3 \mathrm{~A}$ and B and Table 1.
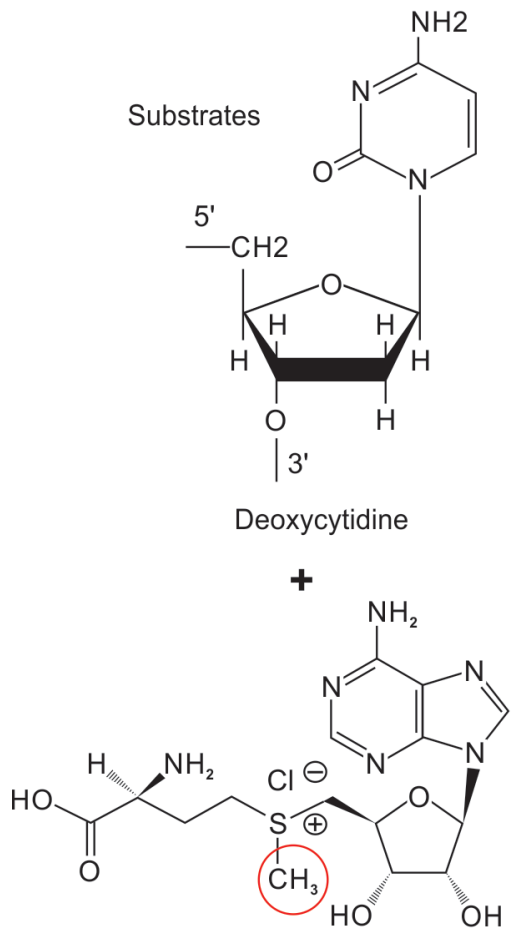

S-adenosyl-L-methionine (SAM)

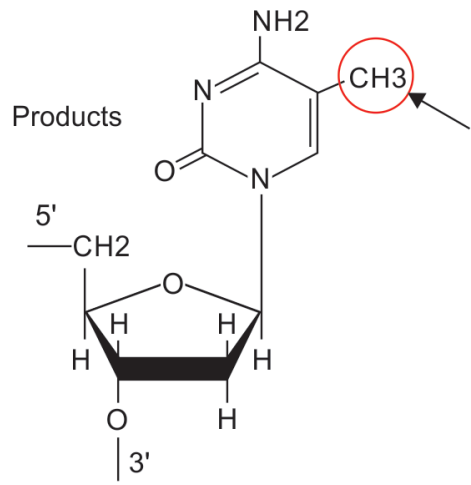

5-Methyl-cytidine
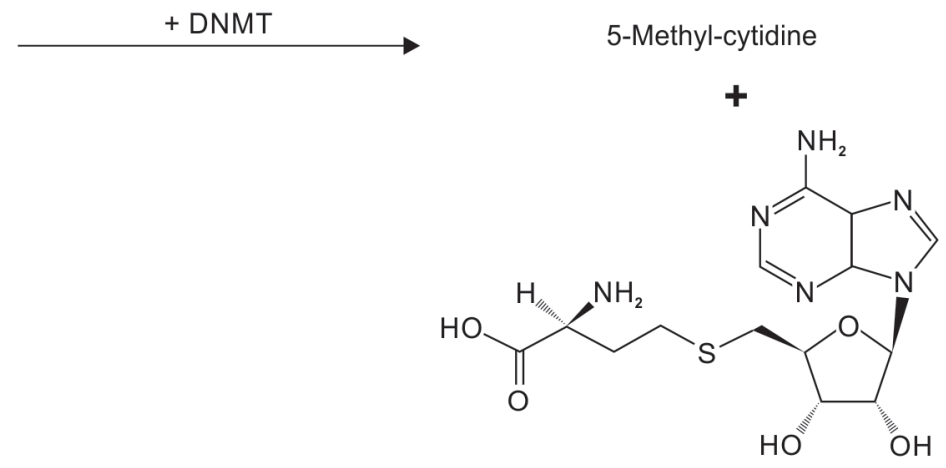

S-adenosyl homocysteine (SAH)

Fig. 1: Methylation of cytosine catalyzed by DNMTs ${ }^{28}$
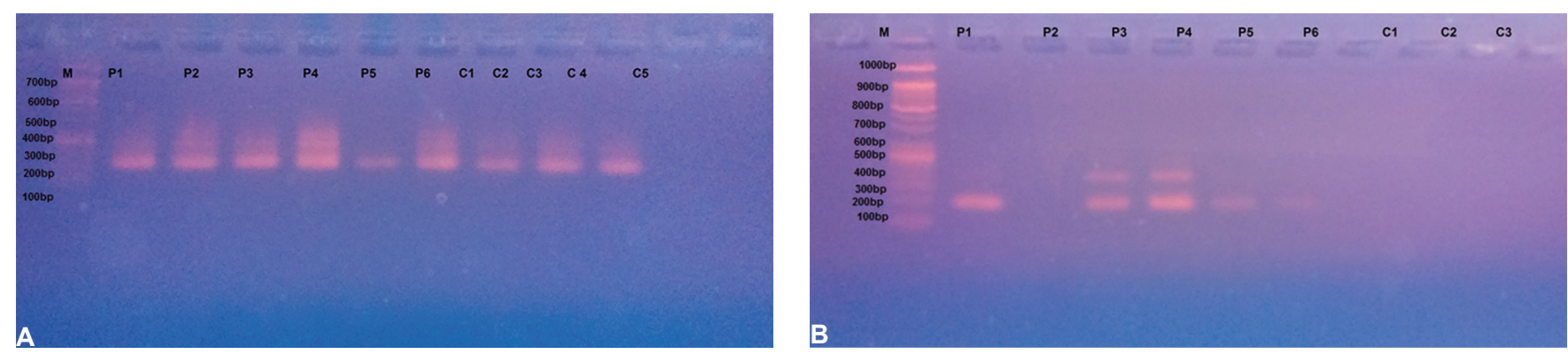

Figs 2A and B: (A) Unmethylated GEL picture of RASSF1A gene; (B) Methylated GEL picture of RASSF1A gene ( $p$ : patient, $c$ : control) in breast cancer ( $p$ : patient, c: control) in breast cancer
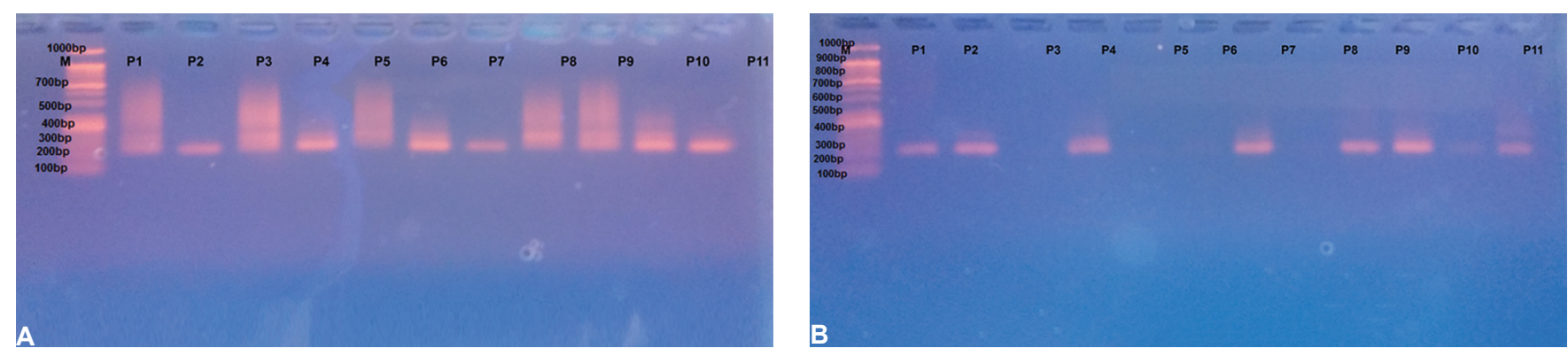

Figs $3 A$ and $B:(A)$ Unmethylated GEL picture of SOX17 gene (p: patient) in breast cancer; (B) Methylated GEL picture of SOX17 gene ( $p$ : patient) in breast cancer 
Table 1: Correlation analysis of RASSF1A gene and SOX17 methylation in breast cancer plasma

\begin{tabular}{lllllll}
\hline $\begin{array}{l}\text { Clinical } \\
\text { information }\end{array}$ & $N$ & RASSF1A M $\%$ & RASSF1A UM $\%$ & SOX17 M $\%$ & SOX17 UM \% & t-test \\
\hline All cases & 50 & $30(60 \%)$ & $20(40 \%)$ & $29(58 \%)$ & $21(42 \%)$ & $\mathrm{p} \leq 0.05$ \\
\hline $\begin{array}{l}\text { Age } \geq 50 \\
<50\end{array}$ & 16 & $11.4(71.2 \%)$ & $5(31.2 \%)$ & $13(81.2 \%)$ & $3(18.7 \%)$ & $\mathrm{p} \leq 0.05$ \\
Stage & 34 & $26(76 \%)$ & $8(23.5 \%)$ & $23(67 \%)$ & $11(32.3 \%)$ & \\
\hline II & 29 & $13(44.8 \%)$ & $16(55 \%)$ & $11(37.9 \%)$ & $18(62 \%)$ & $p \leq 0.05$ \\
III & 15 & $12(80 \%)$ & $3(20 \%)$ & $13(86.6 \%)$ & $2(13.3 \%)$ & \\
IV & 6 & $4(66.6 \%)$ & $2(33.3 \%)$ & $5(83.3 \%)$ & $1(16.6 \%)$ & \\
\hline Menopause & & & & & \\
Pre menopause & 9 & $5(55 \%)$ & $4(44 \%)$ & $6(66 \%)$ & $3(33 \%)$ & $\mathrm{p} \leq 0.05$ \\
Post menopause & 41 & $27.3(65.8 \%)$ & $14(43 \%)$ & $31(75.6 \%)$ & $10(24.3 \%)$ & \\
\hline
\end{tabular}

\section{DISCUSSION}

Solid tumor release into the circulation cfDNA and CTCs which represent promising biomarkers for cancer diagnosis. Circulating tumor DNA may be studied in plasma from cancer patients by detecting tumor-specific alterations, such as genetic or epigenetic modifications association RASSEF1A. RASSEF1A promoter methylation is variably present in breast carcinoma In this study, we investigated the diagnostic performance of RASSF1A promoter methylation in cfDNA as a non-invasive marker of tumor DNA in patients We focused our attention on the methylated form of the marker since it is supposed to represent the fraction of circulating DNA deriving from the tumor by any of the hypothesized mechanisms of necrosis, apoptosis and active release. ${ }^{29} \mathrm{We}$ considered patients at different stages of breast cancer disease to test the reliability of the epigenetic marker under study independently from the stage of the tumor. The absolute levels of the epigenetic marker are significantly higher in breast cancer compared to controls and increases during tumor progression (from in situ to invasive and metastatic disease). To evidence, both the diagnostic and prognostic We found no significant correlation among the two biomarkers analogously to what recently reported in a study on breast cancer patients. ${ }^{30}$ The univariate analysis performed of allowed us to assess the performance of methylated RASSF1A as a marker of tumor-related ctDNA in breast cancer for diagnostic purposes being able to discriminate the in situ and invasive breast cancer from control sand as an indicator of patients prognosis. ${ }^{7}$

The RASSF1A family members were found to be frequently inactivated in many cancers, and such inactivation was correlated with promoter region methylation. ${ }^{31,32}$ The CpG island methylation of RASSF1A was reported in previous studies, ${ }^{33}$ detected a correlation between age and methylation status. ${ }^{34}$
On the other hand, our study found a correlation between tumor stage and differential with RASSF1A. It is well accepted that DNA promoter region methylation could result in loss and alteration of gene expression gene expression in a dose-dependent manner. Therefore, all the combined data from our study confirmed the epigenetic effect on gene expression. These study similar to the studies. ${ }^{35}$ RASSF1A is a tumor suppressor gene silenced by promoter hypermethylation in a variety of human cancers including breast cancer. ${ }^{7}$

SOX17 promoter methylation is variably present in breast carcinoma SOX17, one of the tumor suppressor genes shown to be epigenetically silenced in CTCs of patients with breast cancer. ${ }^{36}$ For this study, we report our findings that SOX17 was epigenetically inactivated and there are differences in levels of methylation between healthy individuals and patients with malignant conditions. We have shown that the SOX17 promoter is highly methylated in primary breast tumors, in cfDNA isolated both from patients with breast cancer and those with metastasis-verified breast cancer. These results to other studies ${ }^{37}$ methylation status of cancerrelated genes is considered to be a promising biomarker for the early diagnosis and prognosis of tumors. This study investigated the methylation status of the SOX17 gene in breast cancer. SOX17 methylation correlated with different stage and lymph node metastasis suggested that epigenetic silencing of SOX17 may also accelerate the spread of cancer through influencing the development of an invasive and biologically aggressive phenotype and thus expedite the progression of breast cancer suggesting that SOX17 methylation in peripheral blood samples may be a good tumor marker for the diagnosis of breast cancer Thus, SOX17 promoter methylation in plasma DNA is highly specific and can provide important prognostic information for patients with breast cancer. SOX17 gene silencing due to promoter methylation may deactivate its tumor suppressor 
role. The tumor-suppressing function of no methylated SOX17 may be partially maintained in patients without SOX17 methylation, and this may slow the progress of tumor development. ${ }^{38}$

\section{CONCLUSION}

Our data indicate that methylation of the RASSAF1A and SOX17 genes are a frequent event in primary breast cancer and that it plays a major role in the silencing of the expression of this gene during tumor development.

\section{ACKNOWLEDGMENT}

Authors would like to thank Al-Diwaniyah Teaching Hospital, Iraq for invaluable assistance for help with preparation of the breast cancer samples.

\section{REFERENCES}

1. Ferlay J, Soerjomataram I, Dikshit R, Eser S, Mathers C, Rebelo $\mathrm{M}$, et al. Cancer incidence and mortality worldwide: sources methods and major patterns in In J Cancer 2015;136(5):E359-386.

2. Siegel R, Naishadham D, Jemal A. Cancer statistics CA Cancer J Clin 2013;63(1):11-30.

3. Qiuqiong T, Jie C, Xue C, Harald S and, Barbara B. Blood-based DNA methylation as biomarker for breast cancer a systematic review. Clinical Epigenetics. 2016;8:115.

4. Hodgson DR, Wellings R, Orr MC, Cormack R, Malone M, Board RE, et al. Circulating tumor-derived predictive biomarkers in oncology: Drug Discover 2009;15:98-101.

5. Fleischer Hacker M, Schmidt B. Circulating nucleic acids (CNAs) and cancer asurvey Biochem Biophysics. Acta 2006;1775:181-232.

6. Jung K, Fleisch Hacker M, Rabien A. Cell-free DNA in the blood as a solid tumor biomarker-a critical appraisal of the literature. Clin Chem Act 2010;411:1611-1624.

7. Francesca S, Claudio O, Daniela M, Vincen zo De G, Marta G, Mario P, et al. Tumor-Related Methylated Cell-Free DNA and Circulating Tumor Cells in Melanoma. Published 2016 Jan;8.

8. Goldberg AD, Allis CD, Bernstein E. Epigenetics: A landscape takes shape Cell 2007;128:635-638.

9. Jones PA. Functions of DNA methylation: Islands start sites gene bodies and beyond. Nat Rev Genet 2012;13:484-492.

10. Maunakea AK, Nagarajan RP, Bilenky M, Ballinger TJ, D'Souza C, Fouse SD, et al. Conserved role of intragenic DNA methylation in regulating alternative promoters. Nature 2010;466:253-257.

11. Rauch TA, Wu X, Zhong X, Riggs AD Pfeifer GP. A human B cell methyl me at100-base pair resolution. Proc Natl Acad Sci USA 2009;106:671-678.

12. Ehrlich M. DNA hypo methylation in cancer cells. Epi genomics 2009;1:239-259.

13. Egger G, Liang G, Aparicio A, Jones, PA. Epigenetics in human disease and prospects for epigenetic therapy. Nature 2004; 429:457-463.

14. Schulz WA, Dokun OY. DNA methylation and human diseases: An overview In DNA and RNA Modification Enzymes:
Structure Mechanism Function and Evolution. Bioscience Austin TX USA 2009:103-116.

15. Donninger H, Clark J, Rinaldo F, Nelson N, Barnoud T, Schmidt ML. The RASSF1A tumor suppressor regulates XPAmediated DNA repair. Mol Cell Biol 2015;35:277-287.

16. Agostini M, Enzo MV, Bedin C, Belardinelli V, Gold in E, Del Bianca $\mathrm{P}$, et al. Circulating cell-free DNA: a promising marker of regional lymph node metastasis in breast cancer patients. Cancer Bio mark 2012;11:89-98.

17. Tanemura A, Terando AM, Sim MS, van Hoesel AQ, Maat MF, Morton DL, et al. CpG island methylate or phenol type predicts progression of malignant melanoma. Clin Cancer Res 2009;15:1801-1807.

18. Marini A, Mirmohammad Sadegh A, Nambiar S, Gustrau A, Ruzicka T, Hengge UR. Epigenetic in activation of tumor suppressor genes in serum of patients with cutaneous melanoma. J Invest Demerol 2006;126:422-431.

19. Koyanagi K, Mori TO' Day SJ, Martinez SR, Hoorn DS. Association of circulating tumor cells with serum tumor-related methylated DNA in peripheral blood of melanoma patients. Cancer Res 2006;66:6111-6117.

20. Roddick S, Mihalcioiu C, Salah RR. Detection methods of circulating tumor cells in cutaneous melanoma: a systematic review Crist Rev On col Hematology 2014;91:74-92.

21. Sinner D, Rankin S, Lee M, Zorn AM. Sox17 and -catenin cooperate to regulate the transcription of endodermal genes. Development. 2004 Jul 1;131(13):3069-3080.

22. Engert S, Burtscher I, Liao WP, Dulev S, Schotta G, Lickert H. Wnt/-catenin signalling regulates Sox17 expression and is essential for organizer and endoderm formation in the mouse. Development. 2013 Jan 1:dev-088765.

23. Li-Jin C, Wiping S, Xiaotian M, et al. SOX17 regulates the Want-beta-catenin signaling pathway in oligodendrocyte progenitor cells. J Neurosis 2011;31:13921-13935

24. Liu Y, Asakura M, Inoue H, Nakamura T, Sano M, Niu Z, et al. Sox17 is essential for the specification of cardiac mesoderm in embryonic stem cells. Proceedings of the National Academy of Sciences. 2007 Mar 6;104(10):3859-3864.

25. Kuok IY, Wu CC, Chang JM, et al. Low SOX17 expression is a prognostic factor and drives transcriptional dyes regulation and esophageal cancer progression. In J Cancer 2014;135:563-573

26. Balgkouranidou, Karayiannakis A, Matthias D. Assessment of SOX17 DNA methylation in cell free DNA from patients with operable gastric cancer. Association with prognostic variables and survival Clin Chem Lab Med. 2013;51:1505-1510.

27. Deyuan F, Chuanli R, Haosheng T. SOX17 Promoter Methylation in Plasma DNA Is Associated With Poor Survival and Can Be Used as a Prognostic Factor in Breast Cancer 2015 Mar;11(94)

28. Ehrlich M, Gama-Sosa MA, Huang LH, Midgett RM, Kuo KC, McCune RA, Gehrke C: Amount and distribution of 5 methyl cytosine in human DNA from different types of tissues of cells. Nucleic Acids Res 1982;10: 2709-2721.

29. Jung K, Fleischhacker M, and Rabien A. Cell-free DNA in the blood as a solid tumor biomarker-a critical appraisal of the literature. Clin Chim Acta. 2010;411:1611-1624.

30. Madic J, Kiialainen A, Bidard FC, Birzele F, Ramey G, Leroy Q. Circulating tumor DNA and circulating tumor cells in metastatic triple negative breast cancer patients. IntJ.Cancer.2015; 136:2158-2165.

31. Kim MS, Lee J, Sidransky D. DNA methylation markers in colorectal cancer. Cancer Metastasis Rev 2010;29:181-206. 
32. Dammann R, Schagdarsurengin U, Strunnikova M, Rastetter M, Seidel C, Liu L, et al. Epigenetic inactivation of the Ras-association domain family 1 (RASSF1A) gene and its function in human carcinogenesis. Histol Histopathol 2003;18: 665-677.

33. Yoon JH, Dammann R, Pfeifer GP. Hyper methylation of the CpG island of the RASSF1A gene in ovarian and renal cell carcinomas. Int J Cancer 2001;94:212-217.

34. Wagner KJ, Cooper WN, Grundy RG, Caldwell G, Jones C, Wadey RB, Morton D, Schofield PN, Reik W, Latif F, Maher ER. Frequent RASSF1A tumor suppressor gene promoter methylation in Wilms' tumor and colorectal cancer. Oncogene 2002;21: 7277-7282.

35. Wei-Wei Z, Lun-De Z, Gao-Xiang W, Xiao-Chun K. Promoter methylation and expression of RASSF1A genes as predictors of disease progression in colorectal cancer. 2016;9(2):20272036

36. Chimonidou M, Strati A, Tzitzira A, Sotiropoulou G, Malamos $\mathrm{N}$, Georgoulias V et al. DNA methylation of tumor suppressor and metastasis suppressor genes in circulating tumor cells. Clin Chem 2011;57:1169-1177.

37. Maria C, Areti S, Nikos M, Vasilis G, and Evi S. Lianidou. SOX17 Promoter Methylation in Circulating Tumor Cells and Matched Cell-Free DNA Isolated from Plasma of Patients with Breast Cancer. 2013.

38. Deyuan F, Chuanli R, Haosheng T, Jinli W, Yuxiang Z. SOX17 Promoter Methylation in Plasma DNA Is Associated With Poor Survival and Can Be Used as a Prognostic Factor in Breast Cancer 2015 Feb;18. 